\title{
НОВЫЙ РОД ВИРУСА ГРИППА Influenza D virus (обзор)
}

\section{А.В. ЛЯПУНОВ $\bowtie$, Г.А. ДАНЧИНОВА}

Вирус гриппа D (IDV), обнаруженный в 2011 году в пробе от свиньи, а затем у крупного рогатого скота (KPC) и других животных, впоследствии был выделен в отдельный род - Influenza D virus (Orthomyxoviridae, Deltainfluenzavirus) (В.М. Hause с соавт., 2014). Предполагается, что IDV произошел от человеческого вируса гриппа C от 300 до 1,5 тыс. лет назад (Z. Sheng с соавт., 2014). Его вирион содержит семь сегментов РНК. Геномные последовательности вируса гриппа D и вируса гриппа C (ICV) различаются на 50 \%, между IDV и ICV не образуются рекомбинанты, а также отсутствует перекрестная реактивность антител (В.М. Нause с соавт., 2011). Ретроспективный анализ выявил, что среди домашних животных вирус начал циркулировать на североамериканском континенте не позднее 2002 года (М. Quast с соавт., 2015). Основным резервуаром патогена служит KРC, но также IDV инфицирует мелких жвачных животных, лошадей, верблюдов, свиней, в том числе в дикой природе. Вирус провоцирует развитие бактериальных инфекций, что может проявляться как поражение паренхимы легких, замедление скорости роста, снижение надоев, задержка вступления в репродукцию. У КРС и коз при тяжелом течении болезни вирус может проникать в кровь через капилляры, выстилающие дыхательные пути. Телята имеют пассивный иммунитет, обусловленный естественным вскармливанием, который ослабевает к 6-8 мес, и животные становятся восприимчивы к инфекции (L. Ferguson с coавт., 2015). Мелкие жвачные животные служат резервуаром вируса и могут передавать инфекцию другим сельскохозяйственным видам (S.L. Zhai с соавT., 2017). Дикие кабаны также могут представлять опасность как переносчики вируса между дикими и домашними животными (L. Ferguson с соавт., 2018). У домашней птицы IDV не выявлен. В настоящее время циркулируют три линии вируса гриппа D. B эксперименте показано, что IDV заражает хорьков (B.M. Hause с соавт., 2011) и морских свинок (С. Sreenivasan с соавт., 2015). У последних он реплицируется как в верхних, так и в нижних дыхательных путях, а также в легких. Кроме этого, возможна прямая передача IDV между морскими свинками. Патоген успешно реплицируется в клетках эпителия дыхательных путей человека при температуре 33-37 ${ }^{\circ} \mathrm{C}$ (M. Holwerda c coaвт., 2019). Показано, что у свиней давление отбора на вирус выше, чем у КРС и коз, поэтому нельзя исключать вероятность того, что при успешной адаптации патогена произойдет его широкое распространение среди домашних свиней, а если учитывать сходство рецепторов свиньи и человека, то и среди людей (Z.Yan с соавт., 2018). Данные о способности IDV инфицировать людей противоречивы, необходимо дальнейшее изучение этого вопроса, причем особое внимание следует уделять лицам, чья деятельность связана с содержанием животных, восприимчивых к новому вирусу. На сегодняшний день патоген широко распространен по планете и представляет потенциальную угрозу для сельского хозяйства в тех странах, где разведение крупного рогатого скота, мелких жвачных животных и свиней имеет большое значение для экономики. Тот факт, что вирус способен поражать широкий круг хозяев, делает его потенциально опасным для людей.

Ключевые слова: вирус гриппа D, вирус гриппа $\mathrm{C}$, крупный рогатый скот, мелкие жвачные животные, свиньи.

Вирусы гриппа представлены четырьмя родами семейства Ortomyxoviridae: Influenza A (Alphainfluenzavirus), Influenza B (Betainfluenzavirus), Influenza C (Gammainfluenzavirus), которые были изолированы в 1930-1940 годах, и Influenza D (Deltainfluenzavirus), обнаруженный в 2011 году в пробе от свиньи, а затем у крупного рогатого скота (КРС) и других животных (13). Разделение по родам связано с отсутствием перекрестных серологических реакций, определяемых антигенными свойствами внутренних белков вириона (рибонуклеопротеинов).

Вирусы гриппа способны инфицировать и вызывать заболевание у человека, ряда млекопитающих, птиц и, возможно, у представителей других классов. Одна из особенностей патогена - его способность преодолевать межвидовой барьер $(4,5)$. Изменчивость определяется двумя механизмами: генетическим дрейфом (точечные мутации) и реассортацией, 
возникающей, когда разные вирусы оказываются внутри клетки и реплицируются, а при сборке вириона происходит объединение сегментов исходных штаммов и возникает патоген с новыми свойствами (6). Как следствие, при встрече с измененным вирусом иммунная система организма не обеспечивает полноценную защиту, что ведет к повторному заболеванию (7). Этот вирус распространяется в популяции, вызывая тяжелую пандемию, что было не раз в истории человечества (8-10).

В представленном обзоре проанализированы работы последних лет по исследованию нового вируса гриппа Influenza D virus, описана ситуация с распространением патогена по земному шару и представлен состав видов, чувствительных к нему.

В настоящее время наибольшее распространение, разнообразие и эпидемиологическое значение имеют вирусы гриппа A (IAV), различающиеся по двум поверхностным белкам - гемагглютинину и нейраминидазе (18 и 11 субтипов). Резервуаром IAV служат водоплавающие птицы, за исключением вирусов с антигенной формулой H17N10 (11) и H18N11 (12), которые выявлены только у рукокрылых $(13,14)$. IAV изолированы от большого числа видов диких и домашних животных. При этом довольно редки сообщения об инфекции у КРС по сравнению с другими сельскохозяйственными млекопитающими (15). За многолетнюю историю наблюдений случаи инфицирования жвачных копытных IAV описаны в небольшом числе работ. Одним из первых было сообщение об обнаружении антител к H3N2 у яков в Непале в 1974 году (16), в 1977 году IAV выделили у теленка (17). В дальнейшем показано, что IAV поражает различные виды домашних жвачных животных, не вызывая массовых тяжелых заболеваний $(18,19)$, но приводя к снижению надоев $(20,21)$. В ряде исследований у КРС обнаружены антитела к так называемым вирусам сезонного гриппа человека (H1N1 и H3N2) (22-24). Экспериментально установлено, что вирус гриппа лошадей Н3N8 успешно реплицируется в первичной культуре клеток респираторного эпителия быка (25), а вирус H5N1, выделенный от кошки, - у живых телят (26).

В человеческой популяции циркулируют две антигенно различающиеся линии вируса гриппа B (IBV) - Victoria и Yamagata (27), способные к реассортации (28). Первичный хозяин - человек, но с 1999 года вирус изолируют от тюленей (Phoca vitulina) $(29,30)$, а в последнее десятилетие появилась информация о передаче патогена домашним животным (31). Вирусы гриппа C (ICV) широко распространены среди людей. Как правило, заболевание протекает бессимптомно либо наблюдается легкое респираторное расстройство у детей в возрасте до 6 лет $(32,33)$. Описаны шесть генетически и антигенно различных линий (34), образующих реассортанты при совместной циркуляции (35). Основной резервуар - человек, хотя имеются сведения о выявлении ICV у домашних свиней $(36,37)$ и собак $(38,39)$. В экспериментах на свиньях показана передача вируса от одного животного к другому $(40,41)$. Возможна передача вируса между людьми и свиньями в естественных условиях (42). Недавно обнаружено, что антитела к ICV имеют верблюды (43), а в 2016 году у больного теленка в США изолирован ICV, который был схож с вирусами гриппа человека на $95 \%(44,45)$.

Обнаружение нового рода вируса гриппа. Вирус гриппа D/swine/Oklahoma/1334/2011 (D/OK), выделенный в апреле 2011 года в штате Оклахома от 15-недельной свиньи с симптомами гриппоподобного заболевания, лишь на 50 \% был подобен человеческим ICV. Первоначально новый вариант обозначили как C/OK. Вирион этого вируса, как и ICV, 
содержит семь сегментов вирусной РНК. В дальнейшем филогенетический анализ показал, что расхождение между ICV человека и C/OK аналогично таковому между вирусами гриппа А и В. В реакции торможения гемагглютинации не было выявлено перекреста между ICV человека и C/OK. Скрининг образцов сывороток крови свиньи и человека выявил, что соответственно 9,5 и 1,3\% имели диагностические титры антител к вирусу С/OK. Исследования клеточной культуры показали, что вирус C/OK проявляет более широкий клеточный тропизм, чем ICV. В клетках ST (клеточная линия яичка свиньи) на 3-и сут этот вирус, как и вирус гриппа, вызывал цитопатические эффекты. Кроме этого, новый вирус было легче культивировать в сравнении с ICV (1). В эксперименте установлено, что ICV и C/OK не способны образовывать реассортанты. На этом основании авторы предложили классифицировать новую группу как вирус гриппа D (IDV) - отдельный род семейства Orthomyxoviridae (46).

Впоследствии было показано широкое распространение IDV на других континентах и способность инфицировать другие виды млекопитающих (КРС, коз, овец и др.). Этот факт свидетельствует о потенциальной угрозе IDV для сельского хозяйства и здоровья людей во всем мире, в том числе в Российской Федерации, странах бывшего СССР, Монголии, где разведение КРС, мелких жвачных животных и свиней имеет важное значение для экономики.

Распространение и хозяева вирусов гриппа D. Первый изолят IDV получен от свиньи, но дальнейшие исследования показали, что основная роль в циркуляции IDV принадлежит $\mathrm{KPC}(47,48)$. В настоящее время IDV обнаружен у КРС в Китае (49), Франции (3), США (50), Италии (51), Мексике (52), Японии (53), Ирландии (54), Люксембурге (55), Великобритании (56). IDV играет важную роль в комплексе респираторных заболеваний KPC (Bovine Respiratory Disease Complex, BRDC) и может существенно снижать показатели продуктивности. Наиболее вероятно, что IDV провоцирует развитие бактериальных инфекций (57), что может проявляться как поражение паренхимы легких, замедление скорости роста, задержка вступления в репродукцию. Гибель животных, снижение производства молока и мяса, траты на лечение причиняют огромные убытки экономике хозяйств.

После открытия первого вируса В.M. Hause с соавт. (46) получили пять изолятов на клеточных культурах, которые более чем на $96 \%$ были идентичны вирусу D/swine/Oklahoma/1334/2011. Зараженность животных составила $18 \%$. В дальнейшем L. Ferguson с соавт. (50) показали, что 68-месячные телята массово заражаются в пунктах предпродажного размещения (Миссисипи, США). К этому возрасту пассивный иммунитет, обусловленный естественным вскармливанием, ослабевает и телята становятся восприимчивы к инфекции. В пункте сбора телят вирус был обнаружен у 2,4 \% здоровых особей и у 23,6 \% животных с симптомами BRDC (50).

В разных странах (США, Франция, Италия, Ирландия, Великобритания) при исследовании вспышек респираторных заболеваний у КРС, в том числе связанных с гибелью животных, обнаруживают IDV. Taк, E.A. Collin c соавт. (2) выявили его у 4,8 \% больных животных из Канзаса, Техаса и Небраски, установили одновременную циркуляцию двух линий, представленных D/swine/Oklahoma/1334/2011 (D/OK) и D/bovine/Oklahoma/660/2013 (D/660), и возможность реассортации между вирусами этих двух линий (2). M.F. Ducatez c соавт. (3) исследовали архивные образцы КРС (2010-2014 годы) и доказали, что по крайней мере с 2011 года IDV циркулирует во Франции. В долине реки По (Северная Италия) также удалось изолиро- 
вать IDV во время вспышек респираторных заболеваний (51). В 12 провинциях Италии 6,5 \% особей (из 895 павших животных) погибли от вируса гриппа D (58).

В 2014-2016 годах в Ирландии у КРС с клинически диагностированными респираторными заболеваниями в мазках из носа был обнаружен IDV (54). В Великобритании у 8,7 \% погибших животных с синдромами респираторных инфекций в качестве единственного вирусного агента, как правило, обнаруживали вирус гриппа D, всегда сочетающийся с бактериальной инфекцией (56). К настоящему времени все вирусные последовательности, описанные в европейских странах, сгруппированы в кладе D/swine/Oklahoma/1334/2011.

Ученые из Китая установили, что на их территории IDV распространился не позднее 2014 года. При скрининговом исследовании животных, не имевших признаков заболевания, РНК вируса встречалась в 0,7$2 \%$ случаев, что свидетельствует о бессимптомном течении инфекции (49, 59). А при исследовании назальных смывов у КРС с различными клиническими проявлениями заболеваний в 2016 году S.L. Zhai с соавт. (59) показали наличие вируса в 12,8 \% случаев у голштинской породы и в 7,3 \% у местного желтого КРС и установили проникновение вируса в систему кровообращения через капилляры, выстилающие дыхательные пути. Гомология изолятов из Китая варьировала от 95,35 до 99,22 \% в сравнении с американскими (49).

Важным показателем распространенности IDV служит степень серопревалентности животных. В 2014 году В.М. Hause с соавт. (46) с использованием в качестве антигенов D/OK и D/660 обнаружили у KРC из разных штатов геометрические средние титры для обоих вирусов в разведении 1:40 и выше. Также интересные результаты получили J. Luo с соавт. (60) при ретроспективном исследовании сывороток крови взрослых животных из штата Небраска (США) в 2003-2004 годах. На всех 40 случайно выбранных фермах были выявлены особи с антителами к IDV (81,9 \%), что стало свидетельством его распространения как минимум с 2003 года. В 2014 году в парных сыворотках 242 телят в возрасте 1 нед оказалось $98 \%$ серопозитивных проб на IDV, в возрасте 3 мес - 76 \%, при этом титры антител у большинства снизились. Эти результаты доказывают, что новорожденные телята имеют высокое содержание материнских антител против IDV. Аналогичные результаты получены в 8 префектурах Японии в 2010-2016 годах: доля положительных проб в среднем составила 30,5 \%, увеличивалась с возрастом животных и не зависела от породы (1267 образцов со 166 ферм). Это значит, что IDV циркулирует в Японии как минимум с 2010 года. В настоящее время вирус распространен в популяциях КРС на территории всей страны (61). В Северной Италии (провинция Мантова) антитела к IDV имели 92,4 \% животных с 42 ферм (58), в Люксембурге - 80,2 \% взрослых животных без симптомов респираторных заболеваний (55), в регионах Франции - от 31 до 70 \% (в среднем 47,2 \%) (62). Также доказано широкое распространение IDV в Северной (Марокко, 2012-2015 годы) и Западной Африке с 2012 года (Того и Бенин, 2014 год) (43). Авторы связывают распространение нового патогена с импортом животных из Европы в Марокко.

Сообщения об изоляции вируса в разных странах в течение последних лет и ретроспективные исследования сывороток крови на наличие антител свидетельствуют о том, что он начал циркулировать у КРС не позднее 2003 года и сегодня распространен на разных континентах. Высокий процент животных, имеющих антитела, позволяет предположить, что 
вирус быстро распространяется и приводит к снижению надоев молока, привеса у молодняка и даже гибели.

Совместное содержание разных видов домашних животных может привести к межвидовой передаче вируса. Так, обследование 648 особей из 141 хозяйства в США и Канаде показало наличие антител к IDV у 5,2 \% овец и 8,8 \% коз (63). При ретроспективном исследовании сывороток крови 64 коз и 85 овец (2001-2007 годы) одна проба от козы содержала антитела к IDV (Массачусетс, 2002 год). Это позволило авторам считать, что в США IDV циркулирует как минимум с 2002 года, а наибольшее распространение получил с 2011 года. Установлено, что на североамериканском континенте мелкие жвачные животные (МЖЖ) имеют антитела к двум линиям, изоляты которых были получены от коровы и свиньи, D/bovine/Oklahoma/660/2013 (D/660) и D/swine/Oklahoma/1334/2011 (D/OK). Можно заключить, что эти виды восприимчивы к новому вирусу и контактировали с ним в разных штатах США и провинциях Канады. E. Salem с соавт. (43) обнаружили антитела к IDV у МЖЖ в Северной (Марокко) и Западной Африке (Того и Бенин) в 2013 году и установили, что вирус подобен D/Bovine/Nebraska/9-5/2012. С помощью ОТ-ПЦР в 2016 году была установлена инфицированность IDV у 33,8 \% коз с различными симптомами заболеваний в Китае (провинция Гуандун) и в случае одного из восьми ректальных мазков от животных с тяжелой формой диареи (59). Во Франции антитела обнаружены у 1,5 \% особей МЖЖ (62). Следовательно, МЖЖ служат резервуаром IDV и могут передавать инфекцию другим видам животных, изменять биологические характеристики вируса, способствовать его эволюции.

Свинья - животное, от которого впервые был изолирован IDV (1). Дикие свиньи мобильны, контактируют с источниками инфекции, прежде всего КРС, и могут распространять вирус. В 2012-2013 годах в штатах Гавайи, Северная Каролина, Оклахома и Техас (США) было установлено, что от 7,8 до 28,6 \% особей в популяциях диких кабанов имели антитела к IDV (64). Также 42,7 \% из 96 серопозитивных к IAV образцов (2010-2013 годы) содержали антитела к IDV. Исследование показало, что дикие кабаны представляют опасность не только в отношении IDV, но и других вирусов как переносчики инфекции между дикими и домашними животными.

IDV активно распространяется среди домашних свиней в США, Италии, Китае, Люксембурге. Во время вспышек респираторных заболеваний в долине реки По (Северная Италия) в мазке из носа свиноматки обнаружена PHK IDV, а впоследствии на клеточных культурах выделен вирус D/swine/Italy/199723-3/2015 (51). Другие авторы во время этой же вспышки исследовали 845 клинических образцов с 448 свиноферм, выявили PHK IDV в 2,3 \% образцов и изолировали три штамма вируса, которые тесно связаны с кластером D/swine/Oklahoma/1334/2011 (65). Также они провели серологический скрининг 3698 сывороток крови свиней из архивных коллекций 2009 года и проб 2015 года и установили, что доля серопозитивных составляла соответственно 0,6 и 11,7\%. В провинции Гуандун (КНР) в 2016 году в назальных смывах положительные пробы были выявлены (ОТ-ПЦР) у 36,8 \% свиней с респираторными симптомами, а в образцах легких погибших свиней доля положительных проб составила 28,9 \% (59). В Люксембурге исследование носовых смывов от здоровых домашних свиней показало низкое распространение вируса - 0 \% в 2009 году и 0,7 \% в 2014-2015 годах, а малая концентрация вирусной РНК в образцах не позволила получить материал для определения нуклеотидных последовательностей (55). Низкая серопревалентность у свиней свидетель- 
ствует о том, что они меньше, чем KPC, участвуют в циркуляции IDV, но в результате эволюции вируса он может стать более опасным для этого вида. Показано, что давление отбора на вирус у свиней выше, чем у КРС и коз (66). Нельзя исключать вероятность того, что успешная адаптация вируса приведет к его повсеместному распространению среди домашних свиней, а учитывая сходство рецепторов свиньи и человека, и среди людей.

Первое сообщение об инфицированности лошадей вирусом гриппа D появилось в 2018 году: две линии IDV совместно циркулировали в популяциях на западе США (67). Антитела были обнаружены в 15,7 \% сывороток крови взрослых лошадей. При этом из 57 позитивных образцов 23 были положительны для обеих линий.

В последние годы появились доказательства инфицированности IDV одногорбых верблюдов в Кении (43) и Эфиопии (68). В некоторых районах Эфиопии до половины верблюдов имеют антитела к IDV, причем как по частоте обнаружения, так и по титрам значения были наибольшими для штамма из Японии (D/bovine/Yamagata/10710/2016) по сравнению с D/swine/Oklahoma/1334/2011 и D/bovine/Nebraska/9-5/2013. При исследовании сывороток крови двугорбых верблюдов в Монголии антитела не обнаружены (68).

В тех случаях, когда различные виды домашних животных содержатся в непосредственной близости друг от друга, находятся на общем выпасе и водопое, частые контакты между ними дают возможность вирусу адаптироваться к новому хозяину. Возможно, это происходит с IDV, который сначала был способен инфицировать КРС, а сейчас его различные линии могут заражать и другие виды млекопитающих. Зная особенности эволюции вируса гриппа на примере других родов, в особенности IAV, нельзя исключить возможность адаптации IDV к человеку. В настоящее время этот вирус, широко распространенный в мире среди домашних животных и способный поражать широкий круг хозяев, потенциально опасен для людей и птиц. Хотя М. Quast с соавт. (63) при исследовании 150 сывороток крови индеек и 100 куриц из 25 птицефабрик в штатах Миннесота и Айова (2014 год) не выявили антител к IDV, однозначно говорить о невозможности заражать птиц нельзя.

Экспериментальное заражение млекопитающих IDV. C началом изучения распространения IDV в разных странах велись работы по экспериментальному заражению домашних и диких свиней, хорьков, морских свинок, КРС. В первом эксперименте использовали свиней в возрасте 2,5 мес. Было показано, что у них вирус D/swine/Oklahoma/1334/2011 реплицируется в носовых раковинах и обнаруживается в назальных мазках. Однако вирус не выявляли в трахее и легких свиней, то есть его репликация могла ограничиваться верхними дыхательными путями. Никаких клинических симптомов и поражений, характерных для гриппа, не наблюдалось. Вирус передавался «чистым» животным при прямом контакте с инфицированными (1). Эксперимент с 4-месячными здоровыми телятами показал вероятность развития инфекции при заражении D/bovine/Mississippi/C00046N/2014, которая характеризовалась умеренными проявлениями признаков заболевания (сухой кашель, течение из носа, вялость). Вирус обнаруживался в носовых раковинах, трахее, бронхах и легком и также передавался контактным путем при совместном содержании зараженных и здоровых телят (48). В аналогичном эксперименте с дикими кабанами, отловленными в природе, была показана передача вируса между животными (64).

Хорька считают одной из лучших моделей для экспериментов с ре- 
спираторными инфекциями среди млекопитающих, поскольку у него развиваются признаки заболевания, сходные с человеком, а также эти животные способны заражаться через аэрозоли. При экспериментальной инфекции D/swine/Oklahoma/1334/2011 обнаружили в носовых раковинах и отсутствовал в нижних дыхательных путях хорька. Имело место заражение в результате прямого контакта животных, но передачу патогена по воздуху не наблюдали. Клинические симптомы и поражения, характерные для IAV, отсутствовали (1). В то же время не было отмечено передачи вируса от телят к хорькам, когда в качестве фомита использовали игрушки, пропитанные выделениями из носа теленка, инфицированного IDV (48). Такая работа была проведена на 30-суточных морских свинках. В отличие от хорьков, у них вирус D/bovine/Oklahoma/660/2013 реплицировался как в верхних, так и в нижних дыхательных путях, а также в легких, но клинических симптомов при этом не наблюдали. Передача вируса от инфицированных животных к «чистым» происходила только при непосредственном контакте (69). Обобщенная информация по восприимчивости к IDV приведена в таблице.

Млекопитающие, восприимчивые к вирусу гриппа D (Influenza D virus, Orthomyxoviridae, Deltainfluenzavirus), методы обнаружения вируса, распространение патогена

\begin{tabular}{|c|c|c|c|}
\hline Вид & Метод детекции & Страна & Ссылки \\
\hline Бык (Bos taurus) & $\begin{array}{l}\text { ОТ-ПЦР, выделение, ИФА, } \\
\text { экспериментальное заражение }\end{array}$ & $\begin{array}{l}\text { США, Китай, Франция, } \\
\text { Италия, Ирландия, Люксем- } \\
\text { бург, Марокко, Того, Бенин }\end{array}$ & $\begin{array}{l}(2,3,43,46- \\
56,58-62)\end{array}$ \\
\hline Буйвол (Bubalus arnee) & ОТ-ПЦР & Китай & $(59)$ \\
\hline Овца (Ovis aries) & ИФА & США, Канада, Того, Бенин & $(43,62,63)$ \\
\hline Коза (Capra hircus) & ОТ-ПЦР, ИФА & $\begin{array}{l}\text { Китай, США, Канада, Того, } \\
\text { Бенин }\end{array}$ & $\begin{array}{l}(43,59,61 \\
62)\end{array}$ \\
\hline Свинья (Sus scrofa) & $\begin{array}{l}\text { ОТ-ПЦР, выделение, ИФА, } \\
\text { экспериментальное заражение }\end{array}$ & $\begin{array}{l}\text { США, Китай, Италия, Люк- } \\
\text { сембург }\end{array}$ & $\begin{array}{l}(1,51,55,59 \\
64,65,79)\end{array}$ \\
\hline Лошадь (Equus ferus caballus) & ИФА & США & $(67)$ \\
\hline $\begin{array}{l}\text { Одногорбый верблюд (Camelus } \\
\text { dromedarius) }\end{array}$ & ИФА & Марокко & $(43,68)$ \\
\hline Хорек (Mustela putorius) & Экспериментальное заражение & & $(1,50)$ \\
\hline Морская свинка (Cavia porcellus) & Экспериментальное заражение & & (69) \\
\hline Человек (Homo sapiens) & ИФА, in vitro & США & $(1,77,78)$ \\
\hline
\end{tabular}

В работе Н. Song с соавт. (70) при изучении гликопротеина гемагглютинин-эстеразы IDV высказаны предположения о механизмах более широкого клеточного тропизма к различным хозяевам в сравнении с ICV.

Происхождение IDV, различия, разнообразие. Несмотря на то, что исследования IAV, IBV и ICV начались в 1930-1940-х годах, IDV был обнаружен только в 2011 году. Вероятно, ранее он циркулировал в ином неизвестном животном (1), а после адаптации к КРС быстро распространился по земному шару. IDV - вирус с отрицательным геномом, имеет структуру, идентичную ICV, его вирион содержит семь сегментов одноцепочечной РНК. Как показали исследования, последовательности IDV и ICV схожи всего лишь наполовину (1), хотя шесть известных линий внутри ICV идентичны на $95 \%$ (34).

IDV имеет четыре структурных белка - M2, M1, NP и белок слияния гемагглютининэстеразу (HEF), три субъединицы РНК-полимеразного комплекса P3, PB1 и РB2 и два неструктурных белка - NS1 и NS2. IDV оболочечный вирус. Внешний слой оболочки вириона представлен липидной мембраной, в ней находится матриксный белок М2, формирующий ионные каналы, и НЕF - оболочечный гликопротеин, проникающий через стенку клетки-жертвы и выполняющий роль гемагглютинина (НА) и 
нейраминидазы (NA), которые имеются у IAV и IBV. Под липидной мембраной расположен матриксный белок M1, который формирует внутренний слой оболочки вируса, придает устойчивость и жесткость внешней липидной оболочке. Геном представлен в виде рибонуклеопротеинового комплекса vRNP (нуклеопротеин в комплексе с геномной PHК вируса), содержит фрагменты РНК, прикрепленные к нуклеопротеину (NP), и три белка полимеразного комплекса - PB1, PB2 и РА $(1,71,73)$.

В экспериментах in vitro убедительных доказательств реассортации ICV и IDV не выявлено. Так, В.M. Hause с соавт. (46), использовав два штамма человеческого ICV - C/Taylor/1947 (C/Tay) и C/Johannesburg/66 $(\mathrm{C} / \mathrm{JHB})$ и штаммы, выделенные от свиньи (D/OK) и коровы $(\mathrm{D} / 660)$, показали, что рекомбинанты возникают только между человеческими вирусами $\mathrm{C} /$ Тау и $\mathrm{C} / \mathrm{JHB}$ и между вирусами животного происхождения $\mathrm{D} / \mathrm{OK}$ и $\mathrm{D} / 660$.

Также было установлено, что IDV демонстрирует иной механизм при продуцировании белка M1 в сравнении c ICV. Другая важная отличительная характеристика штаммов основана на анализе перекрестной реактивности антител. Показано, что между IDV и антисывороткой к ICV такая реактивность отсутствует: поликлональное антитело против С/Тау не распознает антигены вирусов D/OK и D/660, реагируя при этом с антигеном C/JHB. И наоборот, поликлональное антитело D/OK не распознавало вирусы человека (C/JHB и C/Taylor) (46). Другие ученые (67) с помощью кроличьей антисыворотки показали перекрестную реакцию к двум линиям IDV - D/swine/OK/1334/2011 (D/OK) и D/bovine/660/2013 (D/660). В то же время перекрестная реакция к человеческому ICV Victoria/2/2012 (C/Vic) у этих антисывороток отсутствовала. При этом антисыворотка к штамму D/660 была одинаково реактивной по отношению и к D/660, и к D/OK. Антисыворотка против штамма D/OK также перекрестно реагировала с D/660, но была более специфичной в отношении D/OK (титры оказались в 4 раза выше). Исходя из этих различий, Международный комитет по таксономии вирусов (International Committee on Taxonomy of Viruses, ICTV) выделил вирус в отдельный род семейства Orthomyxoviridae - Influenza virus $D$, а штамм D/swine/Oklahoma/1334/2011 рекомендовал как типовой.

Анализ пяти генных сегментов показал, что IDV мог отделиться от ICV от 300 до 1200 лет назад (73). Другие исследователи (74) предполагают, что IDV произошел от человеческого ICV около 1,5 тыс. лет назад. Можно утверждать, что внутри рода есть несколько линий, которые хоть и демонстрируют перекрестную реактивность, но она снижена при использовании гетерологичной сыворотки по сравнению с гомологичной (уменьшение до 10-кратного). По мнению S. Su с соавт. (74), две основные линии, циркулирующие у домашних и диких копытных (D/swine/Oklahoma/1334/2011 и D/bovine/Oklahoma/660/2013), разошлись около 50 лет назад. В мазке из носа коровы с клиническими признаками заболевания S. Murakami с соавт. (53) обнаружили вирус гриппа D (D/bovine/Ibaraki/7768/2016), который имел существенные отличия от IDV, выявленных ранее в Америке, Европе и Китае. В Японии в период вспышки заболевания титры антител в стаде коров были в 4 раза выше к штамму, выделенному в префектуре Ямагата (D/bovine/Yamagata/10710/2016), в сравнении со штаммами из Европы и Америки (75). То есть имеются минимум три одновременно циркулирующие линии IDV. S.L. Zhai с соавт. (59) считают, что наличие вариабельности внутри линии D/660 свидетельствует о продолжающейся эволюции этого вируса. В то же время невысокое число замен, характерное для известных IDV, показывает медленную 
скорость его эволюции. Поверхностный гликопротеин антигенно стабилен, следовательно, новые варианты будут встречаться нечасто, а инфицирование этими вирусами может вызвать длительный иммунитет. Причина медленного эволюционного изменения белков IDV неизвестна. Она может быть связана с низкой частотой ошибок полимераз или с потерей функциональности белков в результате замен аминокислот (74).

Возможная опасность нового вируса для челове ка. Способность IDV инфицировать хорьков, морских свинок и других млекопитающих указывает на широкий круг возможных хозяев этого патогена и потенциальную угрозу для здоровья людей. К настоящему времени имеется немного сведений о способности нового вируса инфицировать людей. Были протестированы 316 образцов сыворотки крови пациентов из Ванкувера (Британская Колумбия, Канада) и Хартфорда (Коннектикут, США), собранные в сезоны гриппа 2007-2008 и 2008-2009 годов. В четырех пробах выявлены антитела к IDV, при этом в трех из них также имелись высокие титры (в разведениях 1:160, 1:320 и 1:1280) к штамму C/Yamagata/10/1981. Один образец имел титр 1:40 к D/OK и был отрицателен к тестируемым штаммам ICV человека (1). Подобным образом в 2011 году исследовали сыворотки крови 220 свиней в возрасте от 3 до 20 нед, в результате в 9,5 \% проб были обнаружены титры к D/OK. Для оценки специфичности использовался ICV человека C/Taylor/1233/47. Только 2,8 \% сывороток свиней имели измеримые титры антител. Следовательно, можно утверждать, что вирус D/OK циркулирует в популяциях свиней, но не характерен для людей (1). Методом ОТ-ПЦР при исследовании архивных образцов, полученных в Шотландии из дыхательных путей человека, был обнаружен только ICV (76). Однако во Флориде (США) в сыворотках крови 35 человек, работающих с КРС, почти в $95 \%$ случаев присутствовали антитела к новому вирусу (штамм D/Bovine/Kansas/135/2010). Также из 11 взрослых людей, не имевших контактов с животными, у двух были обнаружены антитела (77). На модели in vitro эпителия дыхательных путей человека (HАЕС) установлено, что IDV способен эффективно реплицироваться и высвобождаться из клеток при температуре от 33 до $37^{\circ} \mathrm{C}$. При этом репликация происходила без длительной адаптации к использованной в работе культуре клеток и даже более интенсивно, чем у ICV (78).

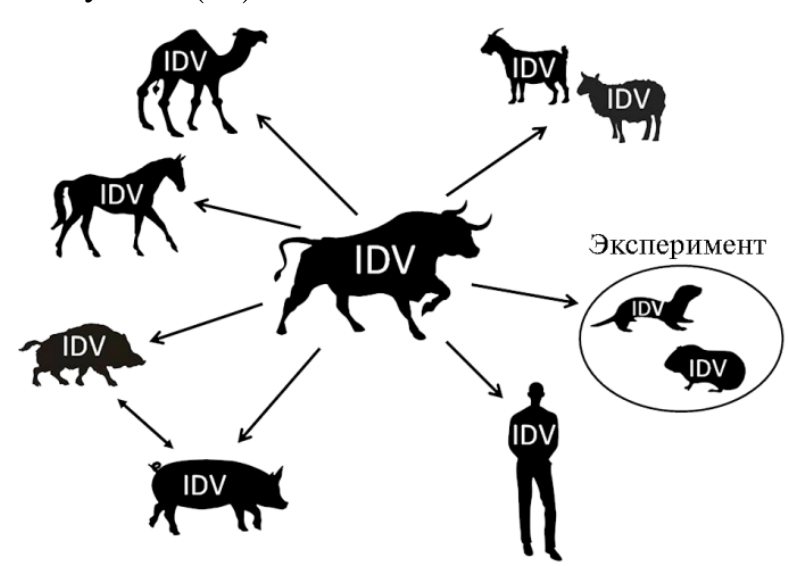

Круг хозяев Influenza D virus (IDV). Стрелками показаны вероятные пути передачи инфекции.

Таким образом, новый вирус гриппа IDV входит в комплекс респираторных заболеваний КРС, имеет широкое распространение в странах Европы, Азии Северной Америки и Африки, оказывает значительное влияние на экономику сельского хозяйства. Установлено, что этот вирус выполняет роль первичной инфекции, провоцируя развитие дальнейшей патологии, размножение патогенных бактерий и колонизацию ими нижних дыхательных путей $(47,52,56,62)$. Кроме КРС 
IDV инфицирует широкий круг домашних животных: коз, овец, свиней, верблюдов, лошадей (рис.). В экспериментах на хорьках и морских свинках доказана восприимчивость и способность передачи вируса $(1,69)$, также он успешно реплицируется в клеточных линиях человека.

Поскольку поголовье домашнего КРС в мире составляет около 1,5 млрд особей, популяции МЖЖ насчитывают более 2,2 млрд, свиней около 1 млрд, лошадей - 61 млн и верблюдов - 35 млн, необходим вирусологический мониторинг не только среди КРС, но и среди других видов домашних животных. Эти виды играют значительную роль в экономике сельского хозяйства многих государств, в том числе России и приграничных стран бывшего СССР. КРС, МЖЖ и свиньи - виды, имеющие большую численность в РФ. По данным Федеральной таможенной службы РФ, с 2014 по 2018 год также на 54 \% вырос импорт КРС (прежде всего племенного, черно-белой голштинской породы из стран ЕС), связанный с несколькими проектами в рамках импортозамещения и нулевой ставкой НДС (до 2019 года) на ввоз в страну племенной продукции (быки-производители, молодняк). В настоящее время нет данных о распространении IDV в РФ и роли патогена в комплексе респираторных заболеваний КРС, но факт обнаружения инфекции в большом числе стран, в том числе граничащих с РФ, позволяет предположить, что имеет место циркуляция вируса и в России. В связи с этим актуальны рекогносцировочные исследования в разных регионах страны, что позволит получить данные, отражающие российскую специфику эволюции и патобиологии IDV.

Поскольку значительное число людей ежедневно контактирует с этими животными, нельзя исключить потенциальную угрозу IDV для здоровья населения. Ретроспективные исследования на свиньях, проведенные в разных странах, показали, что с 2009 года отмечается рост числа иммунных животных $(55,65)$. Несмотря на то, что в настоящее время нет подтвержденных фактов заболевания людей вследствие инфицирования IDV, следует обращать внимание на категории работников, связанных с животноводством, поскольку известны случаи обнаружения вируса у свиней и КРС без признаков заболевания (79).

В популяциях домашних животных одновременно циркулируют минимум три линии IDV (73). Представители разных видов животных часто содержатся совместно, и эти контакты повышают вероятность межвидовых переходов вируса, адаптации к новым хозяевам, ускорения его эволюции и изменения молекулярно-биологических свойств. В 2017 году был разработан метод ОТ-ПЦР в реальном времени для выявления IDV (80), в 2018 году - тест для обнаружения антител у разных видов животных методом иммуноферментного анализа (81). Это дает возможность проводить исследования, позволяющие раскрыть эпидемиологические, биологические и иммунологические аспекты нового патогена и при необходимости создать вакцину для защиты людей от этого вируса. Так как реассортанты IDV могут возникнуть в любое время, велика вероятность появления вирусов, способных к инфицированию людей и передаче от человека к человеку. Поскольку информации о способности IDV инфицировать людей мало, и она противоречива, требуется дальнейшее изучение этой проблемы и проведение серологических и молекулярно-биологических исследований населения, профессионально связанного с уходом за животными, для своевременных мер и предотвращения возможных последствий.

Итак, вирус гриппа D, произошедший от вируса гриппа C человека и первоначально заражавший в основном крупный рогатый скот, в настоящее время широко распространен среди основных копытных сельскохо- 
зяйственных животных на разных материках, патоген также циркулирует в популяциях копытных в дикой природе. Инфицирование этим вирусом может приводить как к бессимптомному течению, так и к тяжелому патологическому процессу, вплоть до гибели животного. Пока нет убедительных данных об инфицировании этим вирусом домашней птицы. В то же время сведения об увеличении генетического разнообразия патогена и росте мирового поголовья кур и другой домашней птицы позволяют предположить возможность межвидового перехода вируса при возникновении подходящих для этого условий, как это ранее было с другими вирусами гриппа. Тот факт, что патоген активно распространяется среди домашних свиней, делает его потенциально опасным и для человека.

\section{ФГБНУ Научный центр проблем здоровья семьи и репродукции человека, \\ Поступила в редакцию \\ 7 октября 2020 года}

664003 Россия, г. Иркутск, ул. Тимирязева, 16,

e-mail: liapunov.asp@mail.ru $₫$, dan-chin@yandex.ru

Sel'skokhozyaistvennaya biologiya [Agricultural Biology], 2021, V. 56, № 2, pp. 215-229

\section{A NEW GENUS OF INFLUENZA VIRUS - Influenza D virus} (review)

\section{A.V. Lyapunov ${ }^{凶}$, G.A. Danchinova}

Scientific Centre for Family Health and Human Reproduction Problems, 16, ul. Timiryazeva, Irkutsk, 664003 Russia, e-mail liapunov.asp@mail.ru ( $₫$ corresponding author), dan-chin@yandex.ru ORCID:

Lyapunov A.V. orcid.org/0000-0002-6947-5771

The authorb declare no conflict of interests

Received October 7, 2020

Danchinova G.A. orcid.org/0000-0002-6705-3070

doi: 10.15389/agrobiology.2021.2.215eng

\section{Abstract}

Influenza D virus (IDV) discovered in swine in 2011 and then in cattle and other animals was subsequently classified as a separate genus Influenza D virus (Orthomyxoviridae, Deltainfluenzavirus) (B.M. Hause et al., 2014). It is assumed that influenza D virus descended from human influenza $C$ virus (ICV) from 300 to 1,500 years ago (Z. Sheng et al., 2014; S. Su et al., 2017). Its virion contains seven segments of RNA. The IDV genome sequence is $50 \%$ different from ICV, no recombinants are formed between IDV and ICV, and no cross-reactivity of the antibodies occurs as well (B.M. Hause et al., 2011). Retrospective analysis showed that the virus has been circulating in North America since 2002 at the latest (M. Quast et al., 2015). Cattle is the main reservoir of the pathogen (L. Ferguson et al., 2015) but it also infects small ruminants, horses (H. Nedland et al., 2018), camels (E. Salem et al., 2017), and pigs (Z. Yan et al., 2018), including in wildlife (L. Ferguson et al., 2018). The virus provokes bacterial infections which affect the lung parenchyma, slowing growth, decreasing milk yields, and causing reproductive delay. In severe acute disease, IDV can move into the bloodstream in cattle and goats via penetration through capillaries lining respiratory tract. Calves possess passive immunity due to natural feeding that weakens in the 6-8-month-old animals, making them susceptible to the infection. Small ruminants serve as a reservoir for IDV and can transmit infection to other livestock. Wild boars can also be dangerous as IDV vectors between wild and domestic animals. IDV has not yet been found in poultry. At present, three types of influenza D virus are circulating simultaneously. The experiments have shown that the virus infects polecats (B.M. Hause et al., 2011) and guinea pigs (C. Sreenivasan et al., 2015). IDV successfully replicates in human's respiratory epithelial cell culture at 33 to $37^{\circ} \mathrm{C}$ (M. Holwerda et al., 2019). The selection pressure for IDV is higher in pigs than in cattle and goats, so IDV, if successfully adapted, can spread widely among pigs. Therefore, a new public health risk could arise given the similarity in receptors between pig and human. The accumulated data on the ability of IDV to infect humans are ambiguous and require further in-deep study. Particular attention should be paid to persons involved in the management of farm animals susceptible to IDV. The pathogen is widespread across the planet and poses a potential threat to agriculture in countries where the breeding of cattle, small ruminants and pigs is of great importance to the economy. The fact that the virus is capable of infecting a wide range of hosts makes it potentially harmful to humans too.

Keywords: influenza D virus, influenza C virus, large cattle, small ruminants, pigs. 
1. Hause B.M., Ducatez M., Collin E.A., Ran Z., Liu R., Sheng Z., Armien A., Kaplan B., Chakravarty S., Hoppe A.D., Webby R.J., Simonson R.R., Li F. Isolation of a novel swine influenza virus from Oklahoma in 2011 which is distantly related to human influenza $\mathrm{C}$ viruses. PLoS Pathogens, 2013, 9(2): e1003176 (doi: 10.1371/journal.ppat.1003176).

2. Collin E.A., Sheng Z., Lang Y., Ma W., Hause B.M., Li F. Cocirculation of two distinct genetic and antigenic lineages of proposed influenza D virus in cattle. Journal of Virology, 2015, 89(2): 1036-1042 (doi: 10.1128/JVI.02718-14).

3. Ducatez M.F., Pelletier C., Meyer G. Influenza D virus in cattle, France, 2011-2014. Emerging Infectious Diseases, 2015, 21(2): 368-371 (doi: 10.3201/eid2102.141449).

4. Taubenberger J.K., Kash J.C. Influenza virus evolution, host adaptation, and pandemic formation. Cell Host \& Microbe, 2010, 7(6): 440-451 (doi: 10.1016/j.chom.2010.05.009).

5. Yoon S.W., Webby R.J., Webster R.G. Evolution and ecology of influenza A viruses. In: Current topics in microbiology and immunology, vol. 385. R. Compans, M. Oldstone (eds.). Springer, Cham, 2014: 359-375 (doi: 10.1007/82_2014_396).

6. Tscherne D.M., García-Sastre A. Virulence determinants of pandemic influenza viruses. The Journal of Clinical Investigation, 2011, 121(1): 6-13 (doi: 10.1172/JCI44947).

7. Francis M.E., King M.L., Kelvin A.A. Back to the future for influenza preimmunity - looking back at influenza virus history to infer the outcome of future infections. Viruses, 2019, 11(2): 122 (doi: 10.3390/v11020122).

8. Potter C.W. A history of influenza. Journal of Applied Microbiology, 2001, 91(4): 572-579 (doi: 10.1046/j.1365-2672.2001.01492.x).

9. Kilbourne E.D. Influenza pandemics of the 20th century. Emerging Infectious Diseases, 2006, 12(1): 9-14 (doi: 10.3201/eid1201.051254).

10. Saunders-Hastings P.R., Krewski D. Reviewing the history of pandemic influenza: Understanding patterns of emergence and transmission. Pathogens, 2016, 5(4): 66 (doi: $10.3390 /$ pathogens5040066).

11. Tong S., Li Y., Rivailler P., Conrardy C., Castillo D.A., Chen L.M., Recuenco S., Ellison J.A., Davis C.T., York I.A., Turmelle A.S., Moran D., Rogers S., Shi M., Tao Y., Weil M.R., Tang K., Rowe L.A., Sammons S., Xu X., Frace M., Lindblade K.A., Cox N.J., Anderson L.J., Rupprecht C.E., Donis R.O. A distinct lineage of influenza A virus from bats. Proceedings of the National Academy of Sciences of the United States of America, 2012, 109(11): 4269-4274 (doi: 10.1073/pnas.1116200109).

12. Tong S., Zhu X., Li Y., Shi M., Zhang J., Bourgeois M., Yang H., Chen X., Recuenco S., Gomez J., Chen L.M., Johnson A., Tao Y., Dreyfus C., Yu W., McBride R., Carney P.J., Gilbert A.T., Chang J., Guo Z., Davis C.T., Paulson J.C., Stevens J., Rupprecht C.E., Holmes E.C., Wilson I.A., Donis R.O. New world bats harbor diverse influenza A viruses. PLoS Pathogens, 2013, 9(10): e1003657 (doi: 10.1371/journal.ppat.1003657).

13. Brunotte L., Beer M., Horie M., Schwemmle M. Chiropteran influenza viruses: flu from bats or a relic from the past? Current Opinion in Virology, 2016, 16: 114-119 (doi: 10.1016/j.coviro.2016.02.003).

14. Campos A.C.A., Goes L.G.B., Moreira-Soto A., de Carvalho C., Ambar G., Sander A.L., Fischer C., Ruckert da Rosa A., Cardoso de Oliveira D., Kataoka A.P.G., Pedro W.A., Martorelli L.F.A., Queiroz L.H., Cruz-Neto A.P., Durigon E.L., Drexler J.F. Bat influenza A(HL18NL11) virus in Fruit Bats, Brazil. Emerging Infectious Diseases, 2019, 25(2): 333-337 (doi: 10.3201/eid2502.181246).

15. Sreenivasan C.C., Thomas M., Kaushik R.S., Wang D., Li F. Influenza a in bovine species: a narrative literature review. Viruses, 2019, 11(6): 561 (doi: 10.3390/v11060561).

16. Graves I.L., Pyakural S., Sousa V.O. Susceptibility of a yak to influenza A viruses and presence of H3N2 antibodies in animals in Nepal and India. Bulletin of the World Health Organization, 1974, 51(2): 173-177.

17. Campbell C.H., Easterday B.C., Webster R.G. Strains of Hong Kong influenza virus in calves. The Journal of Infectious Diseases, 1977, 135(4): 678-680 (doi: 10.1093/infdis/135.4.678).

18. Lopez J.W., Woods G.T. Influenza virus in ruminants: A review. Research Communications in Chemical Pathology and Pharmacology, 1984, 45(3): 445-462.

19. Lopez J.W., Woods G.T. Epidemiological study of swine influenza virus as a component of the respiratory disease complex of feeder calves. Research Communications in Chemical Pathology and Pharmacology, 1986, 51(3): 417-420.

20. Brown I.H., Crawshaw T.R., Harris P.A., Alexander D.J. Detection of antibodies to influenza A virus in cattle in association with respiratory disease and reduced milk yield. The Veterinary Record, 1998, 143(23): 637-638.

21. Gunning R.F., Brown I.H., Crawshaw T.R. Evidence of influenza A virus infection in dairy cows with sporadic milk drop syndrome. The Veterinary Record, 1999, 145(19): 556-557 (doi: 10.1136/vr.145.19.556).

22. Jones-Lang K., Ernst-Larson M., Lee B., Goyal S.M., Bey R. Prevalence of influenza A virus 
(H1N1) antibodies in bovine sera. The New Microbiologica, 1998, 21(2): 153-160.

23. Graham D.A., Calvert V., McLaren E. Retrospective analysis of serum and nasal mucus from cattle in Northern Ireland for evidence of infection with influenza A virus. The Veterinary Record, 2002, 150(7): 201-204 (doi: 10.1136/vr.150.7.201).

24. Crawshaw T.R., Brown I.H., Essen S.C., Young S.C. Significant rising antibody titres to influenza A are associated with an acute reduction in milk yield in cattle. The Veterinary Journal, 2008, 178(1): 98-102 (doi: 10.1016/j.tvjl.2007.07.022).

25. Lin C., Holland R.E. Jr., McCoy M.H., Donofrio-Newman J., Vickers M.L., Chambers T.M. Infectivity of equine H3N8 influenza virus in bovine cells and calves. Influenza and Other Respiratory Viruses, 2010, 4(6): 357-361 (doi: 10.1111/j.1750-2659.2010.00162.x).

26. Kalthoff D., Hoffmann B., Harder T., Durban M., Beer M. Experimental infection of cattle with highly pathogenic avian influenza virus (H5N1). Emerging Infectious Diseases, 2008, 14(7): 1132-1134 (doi: 10.3201/eid1407.071468).

27. Rota P.A., Wallis T.R., Harmon M.W., Rota J.S., Kendal A.P., Nerome K. Cocirculation of two distinct evolutionary lineages of influenza type B virus since 1983. Virology, 1990, 175(1): 59-68 (doi: 10.1016/0042-6822(90)90186-u).

28. Matsuzaki Y., Sugawara K., Takashita E., Muraki Y., Hongo S., Katsushima N., Mizuta K., Nishimura H. Genetic diversity of influenza B virus: The frequent reassortment and cocirculation of the genetically distinct reassortant viruses in a community. Journal of Medical Virology, 2004, 74(1): 132-140 (doi: 10.1002/jmv.20156).

29. Osterhaus A.D.M.E., Rimmelzwaan G.F., Martina B.E.E., Bestebroer T.M., Fouchier R.A.M. Influenza B Virus in Seals. Science, 2000, 288(5468): 1051-1053 (doi: 10.1126/science.288.5468.1051).

30. Bodewes R., Morick D., de Mutsert G., Osinga N., Bestebroer T., van der Vliet S., Smits S.L., Kuiken T., Rimmelzwaan G.F., Fouchier R.A., Osterhaus A.D. Recurring influenza B virus infections in seals. Emerging Infectious Diseases, 2013, 19(3): 511-512 (doi: 10.3201/eid1903.120965).

31. Ran Z., Shen H., Lang Y., Kolb E.A., Turan N., Zhu L., Ma J., Bawa B., Liu Q., Liu H., Quast M., Sexton G., Krammer F., Hause B.M., Christopher-Hennings J., Nelson E.A., Richt J., Li F., Ma W. Domestic pigs are susceptible to infection with influenza B viruses. Journal of Virology, 2015, 89(9): 4818-4826 (doi: 10.1128/JVI.00059-15).

32. Matsuzaki Y., Katsushima N., Nagai Y., Shoji M., Itagaki T., Sakamoto M., Kitaoka S., Mizuta K., Nishimura H. Clinical features of influenza C virus infection in children. The Journal of Infectious Diseases, 2006, 193(9): 1229-1235 (doi: 10.1086/502973).

33. Salez N., Mélade J., Pascalis H., Aherfi S., Dellagi K., Charrel R.N., Carrat F., de Lamballerie $\mathrm{X}$. Influenza $\mathrm{C}$ virus high seroprevalence rates observed in 3 different population groups. The Journal of Infection, 2014, 69(2): 182-189 (doi: 10.1016/j.jinf.2014.03.016).

34. Matsuzaki Y., Mizuta K., Sugawara K., Tsuchiya E., Muraki Y., Hongo S., Suzuki H., Nishimura H. Frequent reassortment among influenza C viruses. Journal of Virology, 2003, 77(2): 871-881 (doi: 10.1128/JVI.77.2.871-881.2003).

35. Peng G., Hongo S., Kimura H., Muraki Y., Sugawara K., Kitame F., Numazaki Y., Suzuki H., Nakamura K. Frequent occurrence of genetic reassortment between influenza $\mathrm{C}$ virus strains in nature. The Journal of General Virology, 1996, 77(7): 1489-1492 (doi: 10.1099/0022-1317-77-71489).

36. Yamaoka M., Hotta H., Itoh M., Homma M. Prevalence of antibody to influenza C virus among pigs in Hyogo Prefecture, Japan. The Journal of General Virology, 1991, 72(3): 711-714 (doi: 10.1099/0022-1317-72-3-711).

37. Brown I.H., Harris P.A., Alexander D.J. Serological studies of influenza viruses in pigs in Great Britain 1991-2. Epidemiology and Infection, 1995, 114(3): 511-520 (doi: $10.1017 / \mathrm{s} 0950268800052225)$.

38. Manuguerra J.C., Hannoun C., Simyn F., Villar E., Cabezas J.A. Natural infection of dogs by influenza C virus: a serological survey in Spain. The New Microbiologica, 1993, 16(4): 367-371.

39. Horimoto T., Gen F., Murakami S., Iwatsuki-Horimoto K., Kato K., Akashi H., Hisasue M., Sakaguchi M., Kawaoka Y., Maeda K. Serological evidence of infection of dogs with human influenza viruses in Japan. The Veterinary Record, 2014, 174(4): 96 (doi: 10.1136/vr.101929).

40. Guo Y.J., Jin F.G., Wang P., Wang M., Zhu J.M. Isolation of influenza C virus from pigs and experimental infection of pigs with influenza C virus. The Journal of General Virology, 1983, 64(1): 177-182 (doi: 10.1099/0022-1317-64-1-177).

41. Yuanji G., Desselberger U. Genome analysis of influenza C viruses isolated in 1981/82 from pigs in China. The Journal of General Virology, 1984, 65(11): 1857-1872 (doi: 10.1099/00221317-65-11-1857).

42. Kimura H., Abiko C., Peng G., Muraki Y., Sugawara K., Hongo S., Kitame F., Mizuta K., Numazaki Y., Suzuki H., Nakamura K. Interspecies transmission of influenza C virus between humans and pigs. Virus Research, 1997, 48(1): $71-79$ (doi: 10.1016/s0168-1702(96)01427-x).

43. Salem E., Cook E.A.J., Lbacha H.A., Oliva J., Awoume F., Aplogan G.L., Hymann E.C., Muloi D., Deem S.L., Alali S., Zouagui Z., Fèvre E.M., Meyer G., Ducatez M.F. Serologic evidence for influenza C and D virus among ruminants and camelids, Africa, 1991-2015. Emerging 
Infectious Diseases, 2017, 23(9): 1556-1559 (doi: 10.3201/eid2309.170342).

44. Zhang H., Porter E., Lohman M., Lu N., Peddireddi L., Hanzlicek G., Marthaler D., Liu X., Bai J. Influenza C virus in cattle with respiratory disease, United States, 2016-2018. Emerging Infectious Diseases, 2018, 24(10): 1926-1929 (doi: 10.3201/eid2410.180589).

45. Zhang H., Porter E.P., Lohman M., Lu N., Peddireddi L., Hanzlicek G., Marthaler D., Liu X., Bai J. Complete genome sequence of an influenza $\mathrm{C}$ virus strain identified from a sick calf in the United States. Microbiology Resource Announcements, 2018, 7(1): e00828-18 (doi: 10.1128/MRA.00828-18).

46. Hause B.M., Collin E.A., Liu R., Huang B., Sheng Z., Lu W., Wang D., Nelson E.A., Li F. Characterization of a novel influenza virus in cattle and swine: proposal for a new genus in the Orthomyxoviridae family. mBio, 2014, 5(2): e00031-14 (doi: 10.1128/mBio.00031-14).

47. Ng T.F.F., Kondov N.O., Deng X., Van Eenennaam A., Neibergs H.L., Delwart E. A metagenomics and case-control study to identify viruses associated with bovine respiratory disease. Journal of Virology, 2015, 89(10): 5340-5349 (doi: 10.1128/JVI.00064-15).

48. Ferguson L., Olivier A.K., Genova S., Epperson W.B,, Smith D.R., Schneider L., Barton K., McCuan K., Webby R.J., Wan X.F. Pathogenesis of Influenza D Virus in Cattle. Journal of Virology, 2016, 90(12): 5636-5642 (doi: 10.1128/JVI.03122-15).

49. Jiang W.M., Wang S.C., Peng C., Yu J.M., Zhuang Q.Y., Hou G.Y., Liu S., Li J.P., Chen J.M. Identification of a potential novel type of influenza virus in Bovine in China. Virus Genes, 2014, 49(3): 493-496 (doi: 10.1007/s11262-014-1107-3).

50. Ferguson L., Eckard L., Epperson W.B., Long L.P., Smith D., Huston C., Genova S., Webby R., Wan X.F. Influenza D virus infection in Mississippi beef cattle. Virology, 2015, 486: 2834 (doi: 10.1016/j.virol.2015.08.030).

51. Chiapponi C., Faccini S., De Mattia A., Baioni L., Barbieri I., Rosignoli C., Nigrelli A., Foni E. Detection of influenza D virus among swine and cattle, Italy. Emerging Infectious Diseases, 2016, 22(2): 352-254 (doi: 10.3201/eid2202.151439).

52. Mitra N., Cernicchiaro N., Torres S., Li F., Hause B.M. Metagenomic characterization of the virome associated with bovine respiratory disease in feedlot cattle identified novel viruses and suggests an etiologic role for influenza D virus. The Journal of General Virology, 2016, 97(8): 1771-1784 (doi: 10.1099/jgv.0.000492).

53. Murakami S., Endoh M., Kobayashi T., Takenaka-Uema A., Chambers J.K., Uchida K., Nishihara M., Hause B., Horimoto T. Influenza D virus infection in herd of cattle, Japan. Emerging Infectious Diseases, 2016, 22(8): 1517-1579 (doi: 10.3201/eid2208.160362).

54. Flynn O., Gallagher C., Mooney J., Irvine C., Ducatez M., Hause B., McGrath G., Ryan E. Influenza D virus in cattle, Ireland. Emerging Infectious Diseases, 2018, 24(2): 389-391 (doi: 10.3201/eid2402.170759).

55. Snoeck C.J., Oliva J., Pauly M., Losch S., Wildschutz F., Muller C.P., Hübschen J.M., Ducatez M.F. Influenza D Virus circulation in cattle and swine, Luxembourg, 2012-2016. Emerging Infectious Diseases, 2018, 24(7): 1388-1389 (doi: 10.3201/eid2407.171937).

56. Dane H., Duffy C., Guelbenzu M., Hause B., Fee S., Forster F., McMenamy M.J., Lemon K. Detection of Influenza D virus in bovine respiratory disease samples, UK. Transboundary and Emerging Diseases, 2019, 66(5): 2184-2187 (doi: 10.1111/tbed.13273).

57. Asha K., Kumar B. Emerging influenza D virus threat: what we know so far! Journal of Clinical Medicine, 2019, 8(2): 192 (doi: 10.3390/jcm8020192).

58. Rosignoli C., Faccini S., Merenda M., Chiapponi C., De Mattia A., Bufalo G., Garbarino C., Baioni, L, Bolzoni L., Nigrelli A., Foni E. Infezione da virus influenza D nel bovino in Italia. Large Animal Review, 2017, 23(4): 123-128.

59. Zhai S.L., Zhang H., Chen S.N., Zhou X., Lin T., Liu R., Lv D.H., Wen X.H., Wei W.K., Wang D., Li F. Influenza D virus in animal species in Guangdong Province, Southern China. Emerging Infectious Diseases, 2017, 23(8): 1392-1396 (doi: 10.3201/eid2308.170059).

60. Luo J., Ferguson L., Smith D.R., Woolums A.R., Epperson W.B., Wan X.F. Serological evidence for high prevalence of influenza D viruses in cattle, Nebraska, United States, 2003-2004. Virology, 2017, 501: 88-91 (doi: 10.1016/j.virol.2016.11.004).

61. Horimoto T., Hiono T., Mekata H., Odagiri T., Lei Z., Kobayashi T., Norimine J., Inoshima Y., Hikono H., Murakami K., Sato R., Murakami H., Sakaguchi M., Ishii K., Ando T., Otomaru K., Ozawa M., Sakoda Y., Murakami S. Nationwide distribution of bovine influenza D virus infection in Japan. PLoS ONE, 2016, 11(9): e0163828 (doi: 10.1371/journal.pone.0163828).

62. Oliva J., Eichenbaum A., Belin J., Gaudino M., Guillotin J., Alzieu J.-P., Nicollet P., Brugidou R., Gueneau E., Michel E., Meyer G., Ducatez M.F. Serological evidence of Influenza D virus circulation among cattle and small ruminants in France. Viruses, 2019, 11(6): 516 (doi: 10.3390/v11060516).

63. Quast M., Sreenivasan C., Sexton G., Nedland H., Singrey A., Fawcett L., Miller G., Lauer D., Voss S., Pollock S., Cunha C.W., Christopher-Hennings J., Nelson E., Li F. Serological evidence for the presence of influenza D virus in small ruminants. Veterinary Microbiology, 2015, 180(3-4): 281-285 (doi: 10.1016/j.vetmic.2015.09.005).

64. Ferguson L., Luo K., Olivier A.K., Cunningham F.L., Blackmon Sh., Hanson-Dorr K., 
Sun H., Baroch J., Lutman M.W., Quade B., Epperson W., Webby R., DeLiberto T.J., Wan X.F. Influenza D virus infection in feral swine populations, United States. Emerging Infectious Diseases, 2018, 24(6): 1020-1028 (doi: 10.3201/eid2406.172102).

65. Foni E., Chiapponi C., Baioni L., Zanni I., Merenda M., Rosignoli C., Kyriakis C.S., Luini M.V., Mandola M.L., Bolzoni L., Nigrelli A.D., Faccini S. Influenza D in Italy: towards a better understanding of an emerging viral infection in swine. Scientific Reports, 2017, 7(1): 11660 (doi: 10.1038/s41598-017-12012-3).

66. Yan Z., Wang R., Zhang L., Shen B., Wang N., Xu Q., He W., He W., Li G., Su S. Evolutionary changes of the novel influenza $D$ virus hemagglutinin-esterase fusion gene revealed by the codon usage pattern. Virulence, 2019, 10(1): 1-9 (doi: 10.1080/21505594.2018.1551708).

67. Nedland H., Wollman J., Sreenivasan C., Quast M., Singrey A., Fawcett L., ChristopherHennings J., Nelson E., Kaushik R.S., Wang D., Li F. Serological evidence for the cocirculation of two lineages of influenza D viruses in equine populations of the Midwest United States. Zoonoses and Public Health, 2018, 65(1): e148-e154 (doi: 10.1111/zph.12423).

68. Murakami S., Odagiri T., Melaku S.K., Bazartseren B., Ishida H., Takenaka-Uema A., Muraki Y., Sentsui H., Horimoto T. Influenza D virus infection in dromedary camels, Ethiopia. Emerging Infectious Diseases, 2019, 25(6): 1224-1226 (doi: 10.3201/eid2506.181158).

69. Sreenivasan C., Thomas M., Sheng Z., Hause B.M., Collin E.A., Knudsen D.E., Pillatzki A., Nelson E., Wang D., Kaushik R.S., Li F. Replication and transmission of the novel bovine influenza D virus in a guinea pig model. Journal of Virology, 2015, 89(23): 11990-12001 (doi: 10.1128/JVI.01630-15).

70. Song H., Qi J., Khedri Z., Diaz S., Yu H., Chen X., Varki A., Shi Y., Gao G.F. An open receptor-binding cavity of hemagglutinin-esterase-fusion glycoprotein from newly-identified influenza D virus: basis for its broad cell tropism. PLoS Pathogens, 2016, 12(3): e1005505 (doi: 10.1371/journal.ppat.1005505).

71. Donchet A., Oliva J., Labaronne A., Tengo L., Miloudi M., C A Gerard F., Mas C., Schoehn G., Ruigrok R.W.H., Ducatez M., Crépin T. The structure of the nucleoprotein of Influenza D shows that all Orthomyxoviridae nucleoproteins have a similar NPCORE, with or without a NPTAIL for nuclear transport. Scientific Reports, 2019, 9(1): 600 (doi: 10.1038/s41598-018-37306-y).

72. Peng Q., Liu Y., Peng R., Wang M., Yang W., Song H., Chen Y., Liu S., Han M., Zhang X., Wang P., Yan J., Zhang B., Qi J., Deng T., Gao G.F., Shi Y. Structural insight into RNA synthesis by influenza D polymerase. Nature Microbiology, 2019, 4(10): 1750-1759 (doi: 10.1038/s41564-019-0487-5).

73. Sheng Z., Ran Z., Wang D., Hoppe A.D., Simonson R., Chakravarty S., Hause B.M., Li F. Genomic and evolutionary characterization of a novel influenza-C-like virus from swine. Archives of Virology, 2014, 159(2): 249-255 (doi: 10.1007/s00705-013-1815-3).

74. Su S., Fu X., Li G., Kerlin F., Veit M. Novel influenza D virus: Epidemiology, pathology, evolution and biological characteristics. Virulence, 2017, 8(8): 1580-1591 (doi: 10.1080/21505594.2017.1365216).

75. Odagiri T., Ishida H., Li J.Y., Endo M., Kobayashi T., Kamiki H., Matsugo H., TakenakaUema A., Murakami S., Horimoto T. Antigenic heterogeneity among phylogenetic clusters of influenza D viruses. Journal of Veterinary Medical Science, 2018, 80(8): 1241-1244 (doi: 10.1292/jvms.18-0157).

76. Smith D.B., Gaunt E.R., Digard P., Templeton K., Simmonds P. Detection of influenza C virus but not influenza D virus in Scottish respiratory samples. Journal of Clinical Virology, 2016, 74: 50-53 (doi: 10.1016/j.jcv.2015.11.036).

77. White S.K., Ma W., McDaniel C.J., Gray G.C., Lednicky J.A. Serologic evidence of exposure to influenza D virus among persons with occupational contact with cattle. Journal of Clinical Virology, 2016, 81: 31-33 (doi: 10.1016/j.jcv.2016.05.017).

78. Holwerda M., Kelly J., Laloli L., Stürmer I., Portmann J., Stalder H., Dijkman R. Determining the replication kinetics and cellular tropism of influenza D virus on primary well-differentiated human airway epithelial cells. Viruses, 2019, 11(4): 377 (doi: 10.3390/v11040377).

79. Thieles P., Nolting J.M., Nelson S.W., Mehoke T.S., Howser C., Bowman A.S. Complete genome sequence of an influenza D virus strain identified in a pig with subclinical infection in the United States. Microbiology Resource Announcements, 2019, 8(4): e01462-18 (doi: 10.1128/MRA.01462-18).

80. Faccini S., De Mattia A., Chiapponi C., Barbieri I., Boniotti M.B., Rosignoli C., Franzini G., Moreno A., Foni E., Nigrelli A.D. Development and evaluation of a new real-time RT-PCR assay for detection of proposed influenza D virus. Journal of Virological Methods, 2017, 243: 31 34 (doi: 10.1016/j.jviromet.2017.01.019).

81. Moreno A., Lelli D., Lavazza A., Sozzi E., Zanni I., Chiapponi C., Foni E., Capucci L., Brocchi E. MAb-based competitive ELISA for the detection of antibodies against influenza D virus. Transboundary and Emerging Diseases, 2019, 66(1): 268-276 (doi: 10.1111/tbed.13012). 